\title{
6 Uma experiência com a Modelagem Matemática no Ensino Médio Profissionalizante
}

\author{
Alzenir Virgínia Soistak
}

SciELO Books / SciELO Livros / SciELO Libros

SOISTAK, A. V. Uma experiência com a Modelagem Matemática no Ensino Médio Profissionalizante. In: BRANDT, C. F., BURAK, D., and KLÜBER, T. E., orgs. Modelagem matemática: perspectivas, experiências, reflexões e teorizações [online]. 2nd ed. rev. and enl. Ponta Grossa: Editora UEPG, 2016, pp. 107-130. ISBN 978-85-7798-232-5. Available from: doi: 10.7476/9788577982325.0007. Also available in ePUB from: http://books.scielo.org/id/b4zpq/epub/brandt-9788577982325.epub.

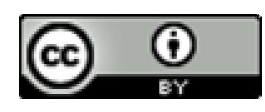

All the contents of this work, except where otherwise noted, is licensed under a Creative Commons Attribution $\underline{4.0 \text { International license. }}$

Todo o conteúdo deste trabalho, exceto quando houver ressalva, é publicado sob a licença $\underline{\text { Creative Commons }}$ Atribição 4.0.

Todo el contenido de esta obra, excepto donde se indique lo contrario, está bajo licencia de la licencia $\underline{\text { Creative }}$ Commons Reconocimento 4.0. 


\section{6}

\section{Uma experiência com a Modelagem Matemática no Ensino Médio Profissionalizante}

Alzenir Virgínia Soistak

\section{Introdução}

Atualmente, nas práticas escolares, a Matemática ao lado da Língua Materna formam juntas as disciplinas básicas dos currículos, desde os primeiros anos de escolaridade, independentemente de raças, credos ou sistemas políticos, recebendo importante destaque na formação dos educandos (MACHADO, 2001). Porém, juntamente com outras disciplinas, contribuem para o pouco êxito do sistema escolar, seja no nível de Educação Infantil, Fundamental, Médio ou Superior, nos quais os problemas educacionais são geralmente identificados e as soluções são difíceis de serem encontradas.

Especificamente no ensino da Matemática, esses problemas educacionais são vivenciados no dia-a-dia da sala de aula, refletindo na aprendizagem dos alunos. Quando da indagação sobre a importância da Matemática aos alunos, eles concordam que a disciplina deve ser ensinada na escola. No entanto confessam que encontram dificuldades de aprendizagem e não conseguem relacionar a Matemática presenciada na escola com a Matemática encontrada em situações do cotidiano.

Refletindo sobre a falta de contextualização e aplicação dos conteúdos matemáticos estudados em sala de aula, constata-se a necessidade de mudanças nas práticas escolares. Mudanças que visem tornar o ensino da Matemática mais significativo, que façam das aulas momentos mais agradáveis, proporcionando aos alunos condições mais eficazes de aprendizagem e de aplicação dos conteúdos aprendidos em situações cotidianas e de atividades profissionais.

Procurando reverter a situação de defasagem no sistema escolar, a Educação Matemática propõe que o ensino da Matemática passe a se constituir em um processo de interação entre professor e aluno, em que ambos possam problematizar, refletir e construir conhecimentos matemáticos (DANTE, 1991).

Na proposição da construção do conhecimento matemático, encontramos metodologias diferenciadas para o ensino da Matemática, como jogos, resolução de problemas, etnomatemática, Modelagem Matemática e outras. Dentre elas a que nos chamou mais atenção e interesse foi a Modelagem 
Matemática, uma alternativa de ensino que busca relacionar e dar significado ao conhecimento empírico do aluno vivido no seu cotidiano com o conhecimento matemático sistematizado na escola, partindo de um tema de seu interesse.

Assim, diante da possibilidade de mudar nossa prática e tornar o ensino mais atraente e mais eficaz, sentimo-nos instigados a experiênciar e analisar os efeitos da Modelagem Matemática em turmas regulares de ensino nas quais atuamos. Para tanto, estabelecemos como objetivo: analisar a experiência com a Modelagem Matemática em situação de sala de aula, ante a contextualização, a aplicabilidade e a compreensão dos conteúdos matemáticos.

Orientados por tal objetivo, desenvolvemos uma atividade de Modelagem Matemática em uma abordagem de característica predominantemente qualitativa, subsidiando-nos a partir do referencial teórico sobre a etnografia voltada ao trabalho escolar (ANDRÉ, 1995). Os dados da investigação foram coletados durante o desenvolvimento da modelagem em duas turmas regulares da primeira série do Ensino Médio Profissionalizante do Colégio Estadual Agrícola Augusto Ribas, Ponta Grossa, Paraná, em dois anos consecutivos, os quais nos conduziram a resultados significativos, contribuindo para uma mudança da prática escolar.

Em decorrência dos encaminhamentos metodológicos adotados na investigação, optamos por apresentar a seguinte estrutura textual deste capítulo: algumas considerações sobre a modelagem na perspectiva adotada, a descrição das atividades nas duas turmas desenvolvidas e algumas reflexões sobre a experiência desenvolvida.

\section{Modelagem Matemática - uma alternativa para o ensino}

A falta de contextualização pela qual está passando o ensino de Matemática nas escolas pode ser atenuada pela adoção da Modelagem Matemática. Um dos princípios dessa prática educativa é partir de temas que sejam do interesse do aluno, fato este que pode, ao mesmo tempo, favorecer a contextualização, haja vista que um assunto de seu interesse, provavelmente, estará relacionado ao seu cotidiano.

Para Burak (1992, p. 62) a Modelagem Matemática “[...] consiste em um conjunto de procedimentos cujo objetivo é construir um paralelo para tentar explicar, matematicamente, os fenômenos presentes no cotidiano do ser humano, ajudando-o a fazer predições e a tomar decisões". Nesse processo o aluno procura ativamente compreender o mundo que o rodeia, 
por meio da sua ação com o objeto, no caso o tema escolhido conforme o seu interesse. $\mathrm{O}$ professor assume o papel de mediador na construção do conhecimento, orientador nas ações a serem realizadas, problematizador ao levantar novas hipóteses e desafiar os estudantes às situações novas e desconhecidas, fazendo com que haja reflexão sobre o que se está tentando fazer.

Para o desenvolvimento dessa metodologia Burak $(1998,2004)$ nos apresenta cinco etapas que proporcionam a significação e formação do conhecimento matemático: escolha do tema, pesquisa exploratória, levantamento dos problemas, resolução dos problemas e o trabalho com os conteúdos no contexto do tema e análise crítica dos resultados encontrados. Essas etapas caminham juntas, num constante ir e vir, pois a reflexão sobre o que se está fazendo é muito importante para o bom êxito do trabalho.

Por meio da Modelagem Matemática há possibilidades de o professor proporcionar um ensino com características construtivistas, pois durante as aulas o aluno é ativo no processo e deve, necessariamente, dialogar com o objeto de conhecimento, para tanto, usa mais aspectos de reflexão e análises do que somente a memorização.

Scheffer e Campagnollo (1998, p. 360) salientam que durante a aplicação da Modelagem Matemática não se pode deixar de lado as características regionais e os interesses que envolvem a vida de nossos alunos. Para esses autores a Modelagem Matemática é:

[...] uma alternativa de ensino-aprendizagem na qual a Matemática trabalhada com os alunos parte de seus próprios interesses e o conteúdo desenvolvido tem origem no tema a ser problematizado, nas dificuldades do dia-a-dia, nas situações de vida. Valoriza o aluno no contexto social que o mesmo está inserido, proporcionando-lhe condições para ser uma pessoa crítica e capaz de superar suas dificuldades.

A formação integral do aluno para atuar em seu contexto social pode ser proporcionada com a utilização da Modelagem Matemática, pois seus problemas e anseios são valorizados na busca da compreensão dos conteúdos matemáticos que estão sendo estudados.

\section{Modelagem Matemática no curso profissionalizante}

No intuito de oferecer um maior significado ao processo de ensino e de aprendizagem da Matemática e, fundamentados pela Modelagem Matemática, é que utilizamos os princípios dessa metodologia alternativa em duas turmas de primeira série do Ensino Médio Profissionalizante em 
que atuamos como professora regente da turma. As orientações e discussões do grupo de pesquisa foram fundamentais para o desenvolvimento de todas as atividades.

Uma primeira turma era composta por 36 (trinta e seis) alunos, com faixa etária variando entre 14 e 16 anos. Nessa turma a Modelagem Matemática foi desenvolvida em duas das quatro aulas semanais, a partir do segundo bimestre de 2004. O tema escolhido através de votação foi a cultura do soja $\mathrm{e}$, sobre esse tema, os alunos reunidos em grupos, pesquisaram o assunto e durante as aulas desenvolveram os conteúdos matemáticos relacionados ao tema e ao currículo proposto para a série.

$\mathrm{Na}$ segunda turma, que estava inicialmente composta por 38 (trinta e oito) alunos com faixa etária variando de 14 a 17 anos, a Modelagem Matemática foi desenvolvida no primeiro semestre de 2005. Essa turma também foi dividida em grupos que escolheram o tema e realizaram a pesquisa. Coincidentemente, o tema escolhido foi o mesmo - cultura do soja, um dos motivos de tal escolha se deu pelo fato de o curso profissionalizante oferecer a formação Técnica em Agropecuária, e assim o interesse da maioria dos alunos estar voltado para agricultura.

Os conteúdos curriculares foram desenvolvidos através de vários questionamentos e reflexões relacionados ao tema escolhido, mostrando a contextualização e aplicabilidade do que se estava estudando.

Os dados coletados pela pesquisadora tiveram como principal fonte a sala de aula, por meio de manifestações espontâneas, questionários, depoimentos, observações, estudos e reflexões sobre a prática escolar cotidiana, durante o desenvolvimento da Modelagem Matemática. Essa é uma das características das investigações qualitativas de cunho etnográfico, em que o professor é também pesquisador, que analisa e interage com seus participantes, afetando e sendo afetado por eles e pelo processo (ANDRÉ, 1995).

\subsection{Desenvolvimento da Modelagem Matemática com a primeira turma}

Para o trabalho com a Modelagem Matemática, iniciamos com uma conversa sobre a importância da Matemática no dia-a-dia e na escola.

Nessa conversa todos concordaram que a Matemática é importante porque está presente em nossa vida e, portanto, necessária de ser aprendida.

Porém, quase que na mesma medida em que a consideram importante muitos alunos a percebem como complicada, difícil, sem graça, chata e confusa, pois envolve vários cálculos e números que, na maioria das vezes, 
não serão aplicados em situações reais. Consequentemente não servirá para nada, oferecendo a sensação de que construída somente para alguns alunos que possuem facilidade em entender, os designados "gênios" da sala de aula.

Após essa conversa, comentamos sobre a forma de encaminhamento do trabalho durante o desenrolar da atividade de Modelagem Matemática e sentimos que os alunos se entusiasmaram com a possibilidade de aprender Matemática de modo mais relacionado com seu cotidiano. Ao escolherem o assunto que iriam estudar, manifestaram a preocupação com a "nota", perguntando se essa metodologia ajudaria a melhorar a nota ao final do bimestre.

Após explanação sobre a Modelagem Matemática, levantamos alguns assuntos que pensamos ser de interesse ao serem estudados. Como o curso é profissionalizante em Agropecuária, os assuntos se voltaram para aqueles que visam ao futuro campo de trabalho dos alunos, como: criação de bovinos, cavalos, aves, agricultura do soja ou milho, clonagem de animais e um grupo sugeriu o histórico do colégio.

$\mathrm{Na}$ impossibilidade de abordar todos os temas sugeridos, passamos a uma votação para que se escolhesse um tema comum à turma, facilitando, naquele momento, o trabalho de professor e alunos e, também, para estabelecer o confronto entre os resultados dos grupos.

Durante a exposição de cada tema houve muita discussão entre os alunos, alguns defendendo o que propuseram e outros mudando de opinião, achando os outros temas interessantes. Nessa aula não foi possível realizar a votação, ficando para a aula seguinte, depois de cada um refletir e definir qual o tema estaria disposto a pesquisar.

Após a votação que teve como tema escolhido - a cultura do soja, os alunos divididos em seis grupos, ficaram responsáveis em coletar os dados que considerassem mais relevantes sobre essa cultura e expor aos demais grupos, interagindo entre eles. Contemplando nesse momento a segunda etapa proposta por Burak (2004).

Nessa etapa, alguns grupos sentiram dificuldades para coleta de dados e na data marcada para começarem as apresentações das pesquisas por cada grupo, essa não havia sido realizada, os alunos alegaram falta de tempo para realizarem a pesquisa, e que o tema era muito amplo e não sabiam o que fazer.

Conversamos novamente sobre o assunto e enumeramos algumas considerações que poderiam ser levantadas na pesquisa, como a área a ser plantada, tipos de sementes, investimento, lucro e outros e um novo prazo foi estipulado para os grupos se organizarem. 
$\mathrm{Na}$ nova data marcada começaram as apresentações de cada grupo sobre vários assuntos, conforme quadro a seguir, que proporcionaram questionamentos e dúvidas. Houve, infelizmente, alguns alunos que ficaram apáticos, não participando das apresentações.

Quadro 1 - Temas abordados sobre a cultura do soja

\begin{tabular}{|c|l|}
\hline Grupos & \multicolumn{1}{|c|}{ Temas abordados } \\
\hline 1 & Importância da análise do solo para o correto plantio da soja; \\
\hline 2 & $\begin{array}{l}\text { Variedades do soja, aumento da produção e sobre o valor nutricional } \\
\text { do grão; }\end{array}$ \\
\hline 3 & Gráfico da margem de lucro, perda e custo da safra do soja; \\
\hline 4 & $\begin{array}{l}\text { Tabela com variação do preço em dólar dos principais produtos } \\
\text { derivados do soja (óleo, farelo e grãos) no intervalo de 1992 a 2004; }\end{array}$ \\
\hline 5 & Principais regiões que cultivam o soja e insumos utilizados nessa cultura; \\
\hline 6 & Fórmula de cálculo para perdas em hectares. \\
\hline
\end{tabular}

Fonte: Alunos

Partindo de um quadro apresentado pela quarta equipe foi levantada a situação de saber estabelecer e montar as porcentagens de aumento e variação que os produtos sofreram durante esses anos. Durante a apresentação dessa tabela os próprios alunos colocaram o problema de saber analisar a variação dos preços e das quantidades produzidas que ali estavam apresentadas de modo mais prático, por porcentagem. Assim, houve a necessidade de aprofundar o assunto de porcentagem e regra de três, complementando esse conteúdo com os exercícios propostos pela apostila.

Quadro parcial apresentado pelo grupo 4:

Quadro 2 - Exportação da soja

\begin{tabular}{|c|c|c|c|}
\hline ANO & PRODUTO & VOLUME (TONELADAS) & VALOR US\$ (TON) \\
\hline 2002 & Grão & 15.970 & 190 \\
\hline 2002 & Farelo & 12.517 & 176 \\
\hline 2002 & Óleo & 1.934 & 402 \\
\hline 2003 & Grão & 18.890 & 216 \\
\hline 2003 & Farelo & 13.602 & 191 \\
\hline 2003 & Óleo & 2.486 & 496 \\
\hline
\end{tabular}

Fonte: Colégio Agrícola. 
Também aproveitamos para fazer uma análise sobre as cotações do dólar em relação às outras moedas sua valorização perante o real e desvalorização perante o euro, por exemplo.

Os estudantes conseguiram com técnicos da própria escola a seguinte informação: "[...] a produtividade média nas lavouras brasileiras se mantém em $800 \mathrm{~kg} / \mathrm{ha}$." Interpretando tal afirmação e de modo intuitivo chegamos à conclusão que conforme a área plantada varia a quantidade de grãos colhidos. Começamos então o conteúdo matemático sobre funções abordando a noção de função, o conceito, a lei de formação e o gráfico representado por essa função em particular.

Quadro 3 - Relação de grãos colhidos pela área plantada

\begin{tabular}{|c|c|c|}
\hline Área (Hectare - Ha) & Grãos (Quilos) & Resultado \\
\hline 1 & 800 & 1 vez 800 \\
\hline 2 & 1600 & 2 vezes 800 \\
\hline 3 & 2400 & 3 vezes 800 \\
\hline$\ldots$ & $\ldots \ldots \ldots \ldots$ \\
\hline$\ldots \ldots$ & $\ldots \ldots \ldots \ldots$ \\
\hline $\mathrm{x}$ & $\mathrm{y}$ & $\ldots \ldots \ldots \ldots$ \\
\hline
\end{tabular}

Fonte: Turma

Nota: Lei matemática que associa grãos e área: $y=800 x$

$y$ - variável dependente: quantidade de grãos (quilos) colhidos por hectare $x$ - variável independente: área (hectares) plantada.

Gráfico 1 - Relação entre Grãos e área Plantada

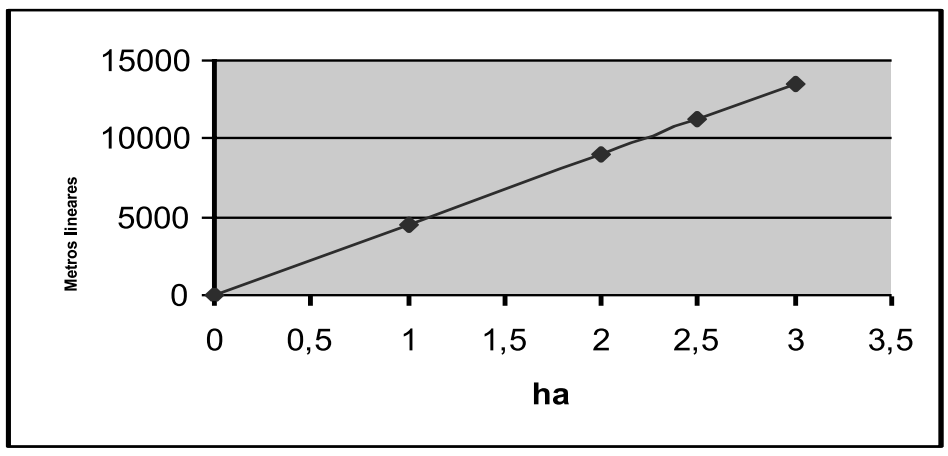

Nota: O domínio dessa função é $\mathrm{D}=\{\mathrm{x} \in \mathrm{R} / \mathrm{x} \geq 0\}$ e o conjunto imagem é $\operatorname{Im}=\{\mathrm{y} \in \mathrm{R} / \mathrm{y} \geq 0\}$. 
Dando continuidade ao assunto de funções, estudamos as funções lineares e quadráticas, conforme variações apresentadas na apostila, relacionando com o tema estudado.

Apesar de o engajamento dos alunos ocorrer de forma tímida por tratar-se de uma experiência nova, a etapa da análise crítica dos resultados permitiu aos alunos desenvolverem sua criticidade e analisarem a validade dos conteúdos matemáticos com a realidade em questão.

Mas como as conclusões e análises demoraram um pouco para acontecer, alguns alunos acostumados com a transmissão de conteúdos por parte do professor e por achar essa maneira mais fácil - ouvir a explicação e resolver os exercícios - propuseram que o professor retornasse aos conteúdos e exercícios da apostila em todas as aulas. Ainda: que a metodologia da Modelagem Matemática fosse abandonada alegando muito trabalho e que tinham que pensar muito nas aulas de matemática.

Conversamos novamente sobre a oportunidade de aprender Matemática de uma maneira diferenciada, por meio da Modelagem Matemática, e que isso poderia ser feito mediante a uma plantação de soja em uma área de 12 alqueires, no colégio. Tal possibilidade despertou novamente o interesse desses alunos, que haviam se desmotivado por algum tempo. Pois já que iriam plantar a soja no colégio, eles poderiam relacionar os conteúdos aprendidos na sala de aula, não só em Matemática, mas também em outras disciplinas, com a prática que lhes estava sendo proporcionada. Dando continuidade a essa etapa, os grupos foram subdivididos a pedido dos próprios alunos que consideraram que em grupos menores, agora com três participantes em cada, haveria um maior entrosamento e participação para realização do trabalho que estava sendo proposto.

Dessa forma, a seguinte situação foi proposta: "fazer o levantamento do que precisa e de quanto precisa para plantar soja numa área limitada por $2 \mathrm{~km}$ de perímetro."

Esse questionamento fez com que os grupos tivessem que encontrar a área em que seria plantada para poderem calcular a quantidade de sementes. As dúvidas e discussões surgidas nos grupos foram muito importantes para despertar um interesse maior no envolvimento para que se resolvesse a situação problema.

Para essa etapa, os próprios alunos sentiram a necessidade de conhecer melhor as medidas agrárias e sobre esse assunto realizaram uma nova coleta de informações. Durante a explanação da coleta de informações o professor questionou junto a eles como surgiram os sistemas de medidas e como fazer 
para realizar tais medidas, bem como levantar relações existentes entre as medidas oficiais (metro e seus derivados) e arbitrárias (litro, braças, palmos...).

O envolvimento da família de alguns alunos foi necessário e muito bem vindo, pois muitos pais originários de regiões agrícolas conhecem as medidas usadas na agricultura (como braça, alqueire, litro) e os alunos questionaram em casa e trouxeram as respostas para discussão e análise em grupo.

Também houve o envolvimento do técnico agrícola do colégio responsável pelo estágio dos alunos nas plantações e da agrônoma e também professora da instituição da disciplina de horticultura ${ }^{1}$ para esclarecimento das dúvidas surgidas para o plantio.

Houve, porém, uma decepção no meio do caminho para alunos e professores envolvidos no projeto da plantação da soja: a área que seria cedida para plantação foi embargada e a plantação não foi executada. Mas o uso dos princípios da Modelagem Matemática fez com que os alunos continuassem seus cálculos e chegassem às conclusões, validações e análises críticas dos seus resultados, mesmo não havendo a prática da plantação da soja.

\subsection{Desenvolvimento da Modelagem Matemática com a segunda turma}

Iniciamos nessa turma da mesma forma, conversando sobre a possibilidade do desenvolvimento da alternativa de ensino pela Modelagem Matemática, e foi possível notar grande expectativa para o ensino realizado desse modo.

Dividimos a turma então em oito grupos, sendo seis grupos com cinco alunos e dois grupos com quatro alunos ${ }^{2}$, que conversaram sobre a sugestão do tema que iria à votação para depois ser realizada a pesquisa e os conteúdos matemáticos a serem estudados.

Os dados sobre os temas sugeridos e a respectiva votação, que foi realizada secretamente após exposição das equipes, seguem conforme Quadro 4:

\footnotetext{
${ }^{1}$ Ambos seriam os responsáveis pela plantação e pelo apoio e atendimento aos alunos em todos os momentos do cultivo da cultura da soja.

${ }^{2}$ Durante o primeiro semestre do ano letivo houve a transferência de sete alunos. Terminamos então a experiência com 4 grupos de 5 alunos, 2 grupos com 4 alunos e 1 grupo de 3 alunos, totalizando 31 alunos.
} 
Quadro 4 - Escolha do tema da modelagem

\begin{tabular}{|c|c|c|}
\hline TEMA & QUANTIDADE DE VOTOS & PORCENTAGEM \\
\hline Bovino & 7 & $18,91 \%$ \\
\hline Soja & 15 & $40,54 \%$ \\
\hline Futsal & 2 & $5,41 \%$ \\
\hline Cesta básica & 2 & $5,41 \%$ \\
\hline Suínos & 4 & $10,81 \%$ \\
\hline Milho & 6 & $16,22 \%$ \\
\hline Equino & 1 & $2,7 \%$ \\
\hline TOTAL & 37 & $100 \%$ \\
\hline
\end{tabular}

Fonte: Turma

Como pudemos perceber, o tema escolhido foi novamente a cultura da soja, talvez isso tenha acontecido porque muitos dos alunos, precisamente em número de 25 , eram filhos de agricultores e possuíam essa cultura em suas propriedades. Além disso, porque a soja é uma das culturas que proporciona boa lucratividade.

Após orientações sobre como se realizaria a coleta de informações sobre o tema, estipulou-se o prazo de 11 dias para cada grupo pesquisar e apresentar os dados considerados importantes sobre o assunto.

Nesse intervalo de tempo destinado à pesquisa, durante as aulas de matemática, estudamos os conteúdos matemáticos conforme apostila adotada pelo colégio, abordando o assunto de conjuntos numéricos.

$\mathrm{Na}$ data marcada começaram as apresentações e o envolvimento dos alunos foi muito bom, havendo vários questionamentos e participação entre as equipes. Como é comum quando se tenta mudar a forma de ensino com a qual se está acostumado, alguns alunos pensaram que era "brincadeira e matação de aula" e não prestaram muita atenção, em alguns momentos chegando a tumultuar a aula.

Quadro 5 - Temas abordados sobre cultura da soja

\begin{tabular}{|c|l|}
\hline Grupos & \multicolumn{1}{c|}{ Temas abordados } \\
\hline 1 & $\begin{array}{l}\text { Breve histórico da soja, produção e produtividade da cultura nos anos de } 1967 \\
\text { a 1973, principais pragas e inseticidas utilizados; }\end{array}$ \\
\hline 2 & Características e composição científica da planta; \\
\hline 3 & Histórico da soja, uso na alimentação e aumento da produção nos estados brasileiros; \\
\hline 4 & Dados econômicos em relação a plantação da soja; \\
\hline 5 & Plantio, manejo e conservação da soja; \\
\hline 6 & Espaçamento entre plantas, vantagens e desvantagens do plantio direto; \\
\hline 7 & Cálculo para determinar possível colheita de grãos; \\
\hline 8 & Desenvolvimento, evolução e cuidados com o plantio da soja. \\
\hline
\end{tabular}

Fonte: Turma 
Após a exposição de todos os grupos, conversamos sobre que problema iríamos abordar em um primeiro momento, e a maioria levantou a questão das medidas agrárias e lineares, de como saber medir corretamente e as relações existentes entre as diferentes medidas. Sobre esse questionamento, começamos a estudar os sistemas de medidas de forma dinâmica com muitos questionamentos e levantamento histórico do surgimento das medidas arbitrárias até se chegar à necessidade de implantação de uma medida oficial. Estudamos então o metro e suas variações em múltiplos e submúltiplos, medidas de superfície e suas relações com as medidas agrárias de grande utilização em suas futuras vidas profissionais.

As medidas agrárias adotam o are como unidade padrão que equivale a $100 \mathrm{~m}^{2}$, tendo apenas um múltiplo denominado de hectare, correspondente a $10.000 \mathrm{~m}^{2}$, e um submúltiplo denominado centiare, que é igual a $1 \mathrm{~m}^{2}$. No entanto, nas medidas de terras, o mais utilizado é o hectare.

Pela lei brasileira $\mathrm{n}^{\mathrm{o}} 1.157$, de 26 de junho de 1862 , é obrigatória a aplicação das unidades de superfície do sistema métrico decimal, porém em muitos lugares do país ainda são empregadas as medidas chamadas antigas, quase todas derivadas da braça, e que possuem características regionais.

As medidas chamadas antigas são as de maior conhecimento dos alunos, consequentemente por terem vindo de regiões agrícolas e estarem acostumados a elas. Porém não sabiam como elas haviam surgido e como se efetuavam suas transformações para o sistema oficial de medida. Assim, o surgimento das medidas não oficiais e sua correspondência em metros quadrados foi estudado, aproveitando a oportunidade para fazer as transformações valendo-se da regra de três simples e construindo um procedimento prático.

Quadro 6 - Medidas agrárias

\begin{tabular}{|c|c|c|}
\hline MEDIDA & SÍMBOLO & EQUIVALÊNCIA \\
\hline Braça quadrada & br quadrada & $2,20 \times 2,20=4,84 \mathrm{~m}^{2}$ \\
\hline Hectare & ha & $100 \mathrm{~m} \times 100 \mathrm{~m}=10000 \mathrm{~m}^{2}$ \\
\hline Alqueire paulista & alq. & $50 \mathrm{br} \times 100 \mathrm{br}=110 \mathrm{~m} \times 220 \mathrm{~m}=24200 \mathrm{~m}^{2}=2,42 \mathrm{ha}$ \\
\hline Quarta & & $25 \mathrm{br} \times 50 \mathrm{br}=55 \mathrm{~m} \times 110 \mathrm{~m}=6050 \mathrm{~m}^{2}=0,605 \mathrm{ha}$ \\
\hline Litro & & $605 \mathrm{~m}^{2}$ \\
\hline
\end{tabular}

Fonte: Turma

As regras de três para as equivalências entre o hectare e o alqueire (1) e entre o hectare e o litro (2) foram construídas da seguinte forma: 


$$
\begin{aligned}
& 1 \mathrm{ha} \rightarrow 10000 \mathrm{~m}^{2} \\
& x(\mathrm{ha}) \rightarrow 24200 \mathrm{~m}^{2} \\
& 10000 x=24200 \\
& x=2,42 \mathrm{ha}
\end{aligned}
$$

$$
\begin{aligned}
& 1 h a \rightarrow 10000 m^{2} \\
& x(h a) \rightarrow 6050 m^{2} \\
& 10000 x=6050 \\
& x=0,605 h a
\end{aligned}
$$

A medida denominada 'quarta', muito utilizada entre os agricultores, corresponde à quarta parte da área conhecida como alqueire $(1 / 4$ do alqueire paulista), assim, dividimos $24.200 \mathrm{~m}^{2}$ por 4 obtemos $6.050 \mathrm{~m}^{2}$. Colocando em representação, temos a Figura 1:

Figura 1 - Representação do alqueire

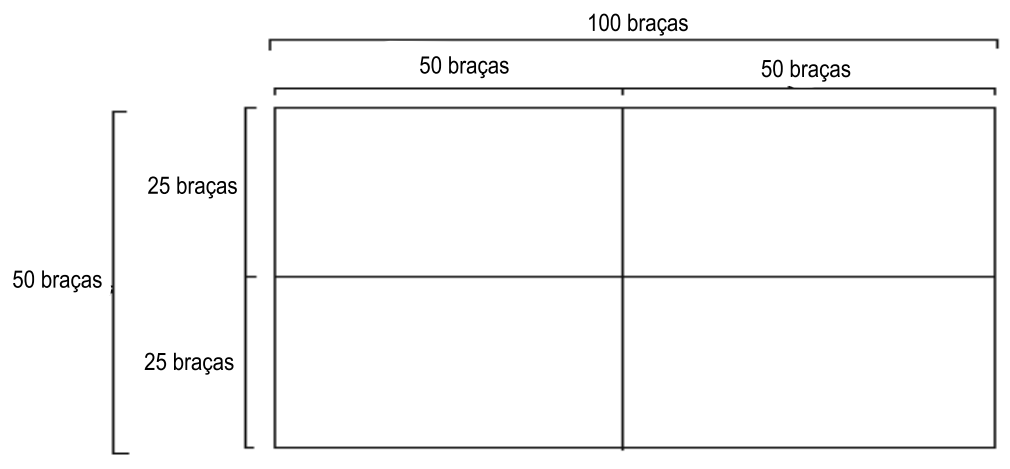

Também relembramos o conceito de fração, operações e simplificação de fração, partindo da interpretação da medida agrária quarta.

$1 / 4+1 / 4=2 / 4=1 / 2$ alqueire;

$2 / 4+1 / 4=3 / 4$ meio alqueire mais uma quarta;

$1 / 4+1 / 4+1 / 4+1 / 4=4 / 4=1$ alqueire.

A medida do litro, que corresponde à região em que se faz a semeadura de um litro (capacidade) de sementes de milho debulhado com espaçamento de um metro quadrado para cada 5 ou 6 grãos, preenchendo, assim, uma área correspondente à $605 \mathrm{~m}^{2}$. Juntando uma área de plantação de 10 litros temos a correspondência de plantação de uma 'quarta'.

De posse dessas informações os alunos reuniram-se em grupos e realizaram transformações de medidas referentes à medida das propriedades que cada aluno possuía. Os conteúdos de razão, proporção, porcentagem, regra de três simples e composta, todos foram aprofundados e relacionados com os exercícios propostos na apostila. 
Dando continuidade foi solicitado aos alunos que elaborassem uma tabela que relacionasse algum assunto da soja, em que os dados de uma coluna estabelecessem uma relação de dependência com a outra, buscando consolidar o conceito de função, a lei de formação matemática da função apresentada e a representação no plano cartesiano. Depois de reunidos em grupos, os alunos apresentaram sua situação e o seu estudo aos demais alunos, o que ensejou várias discussões e análises das funções, assim como sua forma e validade com situações reais.

Segue abaixo o quadro, a lei de formação da função e o gráfico que a representa conforme apresentação dos alunos do GRUPO 1, somente para exemplificar como foi desenvolvida essa parte do trabalho com Modelagem Matemática. Situação considerada: em um hectare são plantados 4500 metros lineares de soja.

Quadro 7 - Quantidade de metros lineares por hectares

\begin{tabular}{|c|c|}
\hline Hectares & Metros Lineares \\
\hline 1 & 4500 \\
\hline 2 & 9000 \\
\hline 2,5 & 11250 \\
\hline 3 & 13500 \\
\hline
\end{tabular}

Nota: Lei de formação: $y=4500 x, \operatorname{com} x \in R_{+}$.

Gráfico 2 - Quantidade de metros lineares por hectares

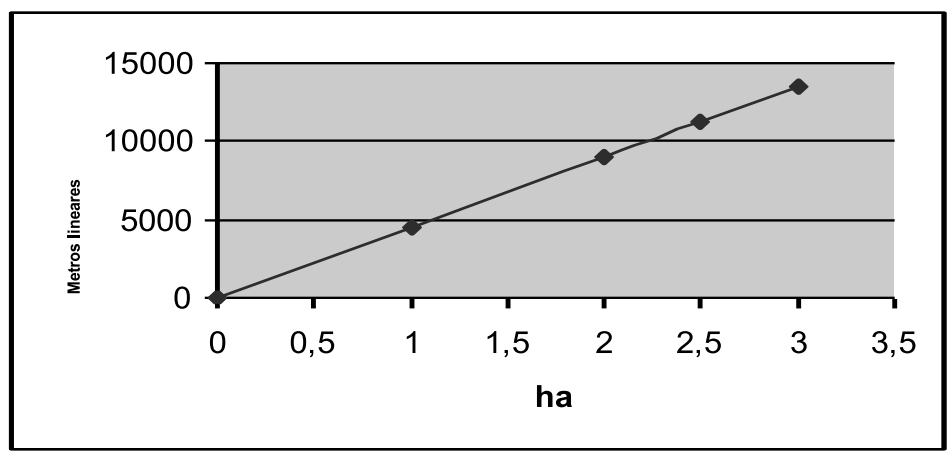

As situações levantadas por todos os grupos giraram em torno das características das funções de primeiro grau, que foram então estudadas e generalizadas para forma da função de $1^{\circ}$ grau $y=a x+b$, e resolvendo os exercícios propostos na apostila. 
Partindo do exemplo da função de um dos grupos $y=100 x$, que representava o preço de um litro de determinado veneno utilizado na cultura da soja, em que o domínio era a quantidade de litros compradas e $y$, a imagem da função (o preço a pagar pela quantidade litros), foi proposto o inverso: com determinada quantia de dinheiro, quantos litros poderiam ser comprados? Todos concordaram que continuaria sendo função, porém domínio e imagem estavam invertidos e então outra lei de formação para a função era necessária e para isso basta trocar $x$ por $y$ e $y$ por $x$ e assim encontrar a função inversa $f^{-1}(x)$ da função dada.

Função dada; $y=100 x$

Função inversa: $x=100 y$

$$
\text { Assim, } y=\frac{x}{100}
$$

Para estudarmos as funções compostas, a seguinte situação problema foi proposta, para que fizessem a lei de formação da função e a representação em diagrama.

Em um hectare são colhidos em média $720 \mathrm{~kg}$ de soja que são ensacados em sacos de $60 \mathrm{~kg}$. Sabendo que cada saco de soja é vendido a $\mathrm{R} \$ 35,00$, e o agricultor paga uma taxa fixa de $\mathrm{R} \$ 100,00$ pelo transporte até a cooperativa, qual a função que representa a receita obtida em função da área plantada?

O problema foi resolvido em duas etapas, primeiramente era necessário saber a função da quantidade de sacos colhidos em relação à área plantada.

$$
s(x)=\frac{720 x}{60} \Rightarrow s(x)=12 x
$$

Representada pelo diagrama: 
Figura 2 - Diagrama

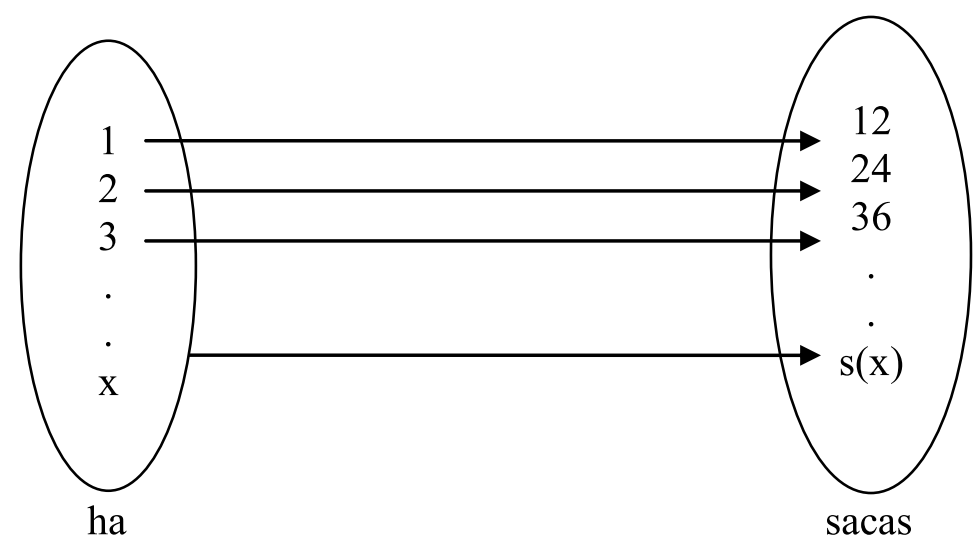

Nota: Sabendo a quantidade de sacos colhidos, encontramos a função da receita obtida. $r(x)=35 x-100$.

Através do diagrama:

Figura 3 - Diagrama

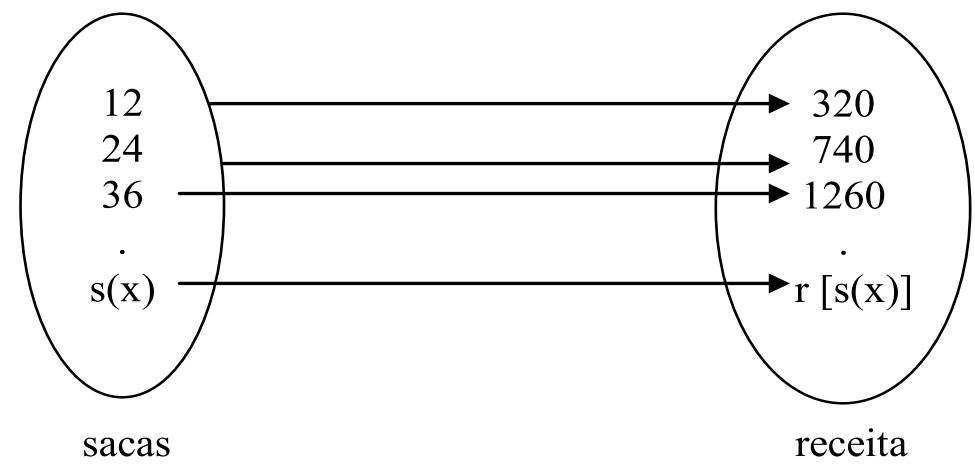

Nota: Observando e analisando as relações, concluímos que a função da receita obtida é encontrada através da função das sacas colhidas, e essa através da área plantada, assim podemos obter a função da receita diretamente relacionada com a área plantada fazendo a função composta da receita com a quantidade de sacas, assim: $r[s(x)]=35(12 x)-100$

$$
r[s(x)]=420 x-10
$$


Figura 4 - Diagrama de Função Composta

ha

receita

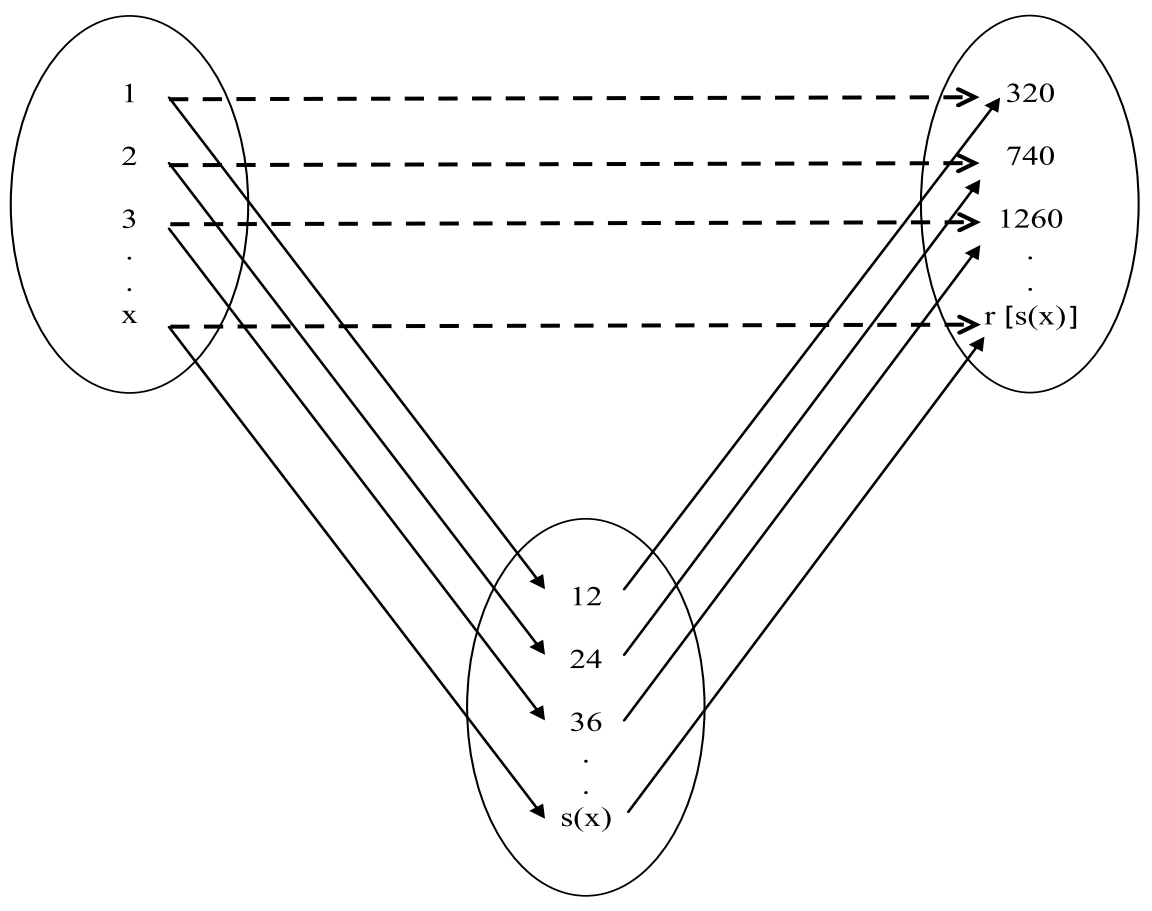

sacas

Compreendendo a função composta pelo exemplo acima, outros exercícios sobre função composta foram propostos e resolvidos.

Para introdução do estudo da função quadrática, usamos como ponto de partida uma situação-problema que foi apresentada aos alunos para que analisassem e resolvessem.

Um agricultor deseja construir um galpão retangular que utilizará para depósito. Para isso ele dispõe de $40 \mathrm{~m}$ de madeira suficientes para cercar o galpão. Utilizando os $40 \mathrm{~m}$ de madeira, quais devem ser as dimensões do galpão de modo a obter a maior área interna possível? 
Figura 5 - Galpão retangular

$20-x$

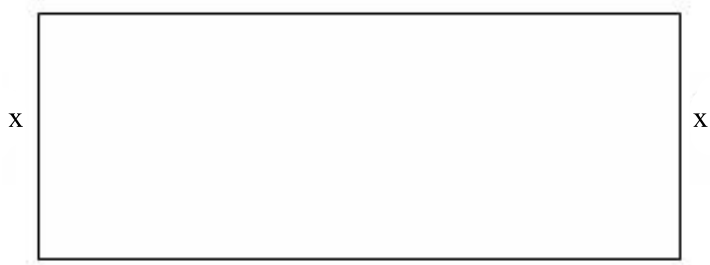

$20-x$

Perímetro, representado por P, é a soma das medidas de todos os lados, então no esquema acima temos:

$$
\begin{aligned}
& P=x+x+(20-x)+(20-x) \\
& P=2 x+2(20-x)
\end{aligned}
$$

Os 40m de madeira serão utilizados para o perímetro do galpão, assim temos que descobrir o valor da base e da altura do retângulo que multiplicados fornecerão a área interna do galpão. Após a construção do esquema acima, chegou-se ao Quadro 8:

Quadro 8 - Área do galpão

\begin{tabular}{|c|c|c|}
\hline Altura do retângulo $-\mathbf{x}$ & Base vezes altura $-\mathbf{( 2 0}-\mathbf{x}) . \mathbf{x}$ & Área do retângulo $-\mathbf{Y}$ \\
\hline 0 & 20.0 & 0 \\
\hline 3 & 17.3 & 51 \\
\hline 5 & 15.5 & 75 \\
\hline 8 & 12.8 & 96 \\
\hline 9 & 11.9 & 99 \\
\hline 10 & 10.10 & 100 \\
\hline 11 & 9.11 & 99 \\
\hline 12 & 8.12 & 96 \\
\hline 15 & 5.15 & 75 \\
\hline 17 & 3.17 & 51 \\
\hline 20 & 0.20 & 0 \\
\hline
\end{tabular}


Pelo quadro a maior área interna obtida no galpão será de $100 \mathrm{~m}^{2}$, a partir das dimensões laterais $10 \mathrm{~m}$ por $10 \mathrm{~m}$.

Conforme a variação da medida do lado, a medida da área também varia, obtemos então uma função, e sua lei de formação pode ser obtida:

$\mathrm{A}=$ base $x$ altura do retângulo

$\mathrm{A}=(20-x) \cdot x$

$\mathrm{A}=20 x-x^{2}$ ou

$y=f(x)=-x^{2}+20 x \rightarrow$ função quadrática ou de $2^{\circ}$ grau

$y=a x^{2}+b x+c \rightarrow$ forma geral da função quadrática, $\operatorname{com} a, b$ e $c \in \mathrm{R}$ e $a \neq 0$

Gráfico 3 - Área Máxima em Função das Medidas Laterais

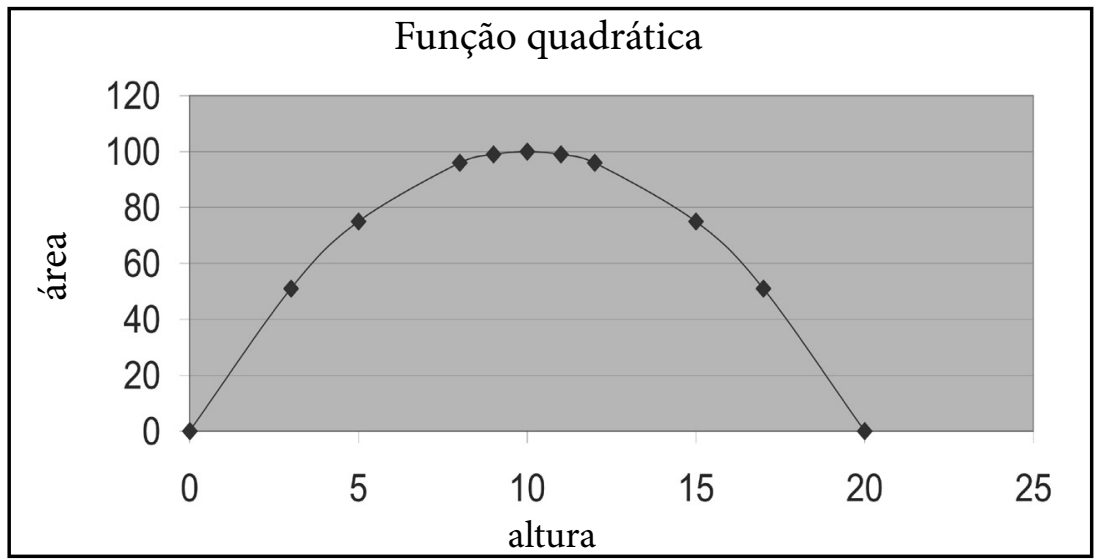

O domínio dessa função é dado por: $\mathrm{D}=\{\mathrm{x} \in \mathrm{R} / 0<\mathrm{x}<20\}$, considerando a necessidade de atribuir significado à situação estudada. A imagem dada por: $\operatorname{Im}=\{\mathrm{y} \in \mathrm{R} / 0 \leq \mathrm{y} \leq 100\}$ é decorrência do domínio estabelecido.

Uma maneira construtiva de encontrar o valor máximo dessa função, foi com o auxílio do quadro anterior, assim, tornou-se fácil visualizar o ponto de máximo ou vértice da parábola, o qual é dado pelas coordenadas: $(\mathrm{x}, \mathrm{y})=(10,10)$. As coordenadas do ponto máximo $x$ e $y$, são obtidas pelas

expressões consagradas $x=\frac{-b}{2 a}$ e $y=\frac{-\Delta}{4 a}$. Assim, o vértice da parábola é dado por $V=\left(\frac{-b}{2 a}, \frac{-\Delta}{4 a}\right)$. 
Ressaltamos que essa atividade fica revestida de significado, uma vez que a situação estudada pode culminar na generalização do conteúdo, o que não impede de estudar outras expressões que possuam pontos de mínimo.

Partindo desse exercício, trabalhamos as particularidades da função quadrática, como vértice, raízes, concavidade da parábola, construção de gráficos, domínio e imagem da função quadrática, discutindo acerca das semelhanças e diferenças das funções de primeiro grau.

Com essas atividades o segundo bimestre do ano letivo foi concluído e, como parte da avaliação, foi solicitado um relatório individual aos alunos, o qual deveria conter considerações sobre o tema abordado, bem como sobre os conteúdos matemáticos estudados nesses dois bimestres, além de uma conclusão com impressões e percepções sobre a intervenção feita com a Modelagem Matemática.

\section{Reflexões sobre a experiência com a Modelagem Matemática}

Analisando as duas experiências da Modelagem Matemática, percebemos que ambas trouxeram um enriquecimento muito significativo à atuação profissional, na medida em que contribuíram para mudança de atitude frente ao ensino da matemática até então ministrada, com exercícios prontos e conteúdos que, muitas vezes, não estavam relacionados com o interesse do aluno.

Apesar do fato de alguns professores desenvolverem algumas atividades diversificadas, essas dificilmente partem do interesse do aluno, ou estão relacionadas a assuntos ligados ao seu cotidiano. Muitas vezes as "situações-problema" são apresentadas como pretexto para iniciar ou para fixar algum conteúdo retirado do livro didático. Não que isso não seja importante, mas sentimos que se as situações surgirem no contexto do trabalho na perspectiva da Modelagem Matemática, elas se apresentarão contextualizadas e mais significativas para o aluno e, por isso, tendem a ser aprendidas de forma mais significativa e compreensiva.

Por um lado, destacamos que o trabalho com a Modelagem Matemática exige muita dedicação por parte do professor, sendo que este muitas vezes não está preparado, devido à formação deficitária recebida na qual não desenvolveu habilidades investigativas. Por outro lado, tendo em vista a excessiva carga horária, não dispõe de tempo para o preparo adequado, frente às situações que emergem das atividades de modelagem, em relação ao tema escolhido. 
Outro ponto a ser considerado nas duas experiências foram os momentos de insegurança por parte do professor, principalmente diante de situações de desconhecimento de uma melhor maneira de envolver os alunos e relacionar os problemas decorrentes do tema escolhido, assim como dar significado aos conhecimentos trazidos do senso comum e relacioná-los com os conteúdos matemáticos mais elaborados.

Um exemplo dessa falta de significado foi quando abordamos a questão da produção de grãos de soja por hectare, relacionando-a com o conteúdo de funções de $1^{\circ}$ grau que constrói a lei de formação, os gráficos e destaca as particularidades desse tipo de função, como: domínio, imagem e raízes. A alegação dos alunos era que se os problemas podiam ser resolvidos de forma mais simplificada, com o conhecimento que eles já possuíam, porque "complicar" com outras formas de resolução? Cabe destacar que os conhecimentos mais elaborados permitem uma resolução mais rápida, porém, só é possível a apropriação quando existe o processo de construção e significação do conteúdo.

Os desafios surgidos durante as etapas da Modelagem foram muitos, principalmente quando nos propusemos desenvolvê-la na primeira turma durante duas aulas, das quatro aulas regulares da disciplina de matemática. Tínhamos o objetivo de, além de tornar o ensino mais atraente, ter que cumprir com o conteúdo programático curricular, diante da cobrança de alguns alunos em ver que a apostila não seria estudada até o final e da falta de tempo para realizar tudo que estava sendo proposto.

$\mathrm{Na}$ segunda turma, a Modelagem Matemática foi desenvolvida em todas as aulas, sem nos preocuparmos com a sequência da apostila, e sim com o desenvolvimento dos conteúdos matemáticos surgidos dentro do tema e conciliando-os aos seus exercícios quando possível, por causa da exigência de alunos, pais e escola.

Esses aspectos mostram que as estruturas de ensino de nossas escolas ainda privilegiam os conteúdos, o mero cumprimento deles, sem a atenção devida ao processo de construção desse conhecimento. Existe a preocupação centralizada no cumprimento de um programa em detrimento da compreensão e do significado. Essas situações evidenciam uma concepção de ensino, de educação e de matemática "[...] conservadora comprometida com a reprodução do autoritarismo, da heteronomia, da submissão passiva e da ausência de crítica" (HOFF, 1996) e que nós professores, muitas vezes, teimamos em conservar.

Uma possibilidade de abertura à mudança pode ser encontrada nos Parâmetros Curriculares Nacionais, as quais indicam a necessidade de mudança nas concepções de ensino que permeiam a escola, para poder 
formar um cidadão competente, capaz de inserir-se no processo produtivo, considerando os diversos contextos em que está inserido.

A integração dos diferentes conhecimentos pode criar as condições necessárias para uma aprendizagem motivadora, na medida em que ofereça maior liberdade aos professores e alunos para a seleção de conteúdos mais diretamente relacionados aos assuntos ou problemas que dizem respeito à vida da comunidade. (BRASIL, 1999, p.36).

Essa abertura à liberdade do professor coloca a necessidade da contextualização e da interdisciplinaridade entre os conteúdos que devem ser ministrados na escola. "O conhecimento espontâneo auxilia a dar significado ao conhecimento escolar. Este último, por sua vez, reorganiza o conhecimento espontâneo e estimula o processo de sua abstração". (Ibidem, p. 95).

Porém, ao mesmo tempo em que essa abertura é dada, os conteúdos curriculares de Matemática são apresentados como os mais importantes. Nesse sentido, orientam que devem ser explorados ao longo da formação do aluno, e ainda alertam para que não haja a supervalorização dos conhecimentos cotidianos “[...] com o risco de perder o essencial da aprendizagem escolar que é seu caráter sistemático, consciente e deliberado". (Ibidem, p. 94).

Além disso, ao final de cada bimestre, a "nota" do aluno em relação ao conteúdo que foi trabalhado é cobrada do professor por alunos, pais e pela escola. Não esquecendo ainda o poder dominador exercido pelo livro didático nas práticas escolares, em que muitas vezes não nos damos conta. O livro apresenta os conteúdos, principalmente os de matemática, de forma linear, conduz de forma equivocada a 'necessidade' de se aprender primeiro um conteúdo para depois o outro. Os conteúdos são apresentados na maioria das vezes em forma de definições e exercícios, tirando do aluno a capacidade de reflexão, organização e construção de conceitos. Os livros ditam o que deve ser aprendido primeiro e quais são os exercícios que devem ser feitos para fixação do conteúdo.

Essas palavras não devem se constituir em motivos de desânimo e razão para desistir, mas mostram os obstáculos que precisam ser encarados e superados, tais como: a concepção de matemática vigente, na qual prevalece a resolução dos exercícios sem um contexto, favorecendo a mera aplicação de fórmulas, memorização e resolução de exercícios mecânicos; a concepção de ensino descontextualizada, em que se privilegia o como fazer em detrimento do porquê fazer. Vencendo tais obstáculos poderemos oferecer uma Educação Matemática mais viva, atuante e crítica aos nossos 
alunos, encontrando significado, utilidade, aplicação da matemática nas situações cotidianas e de enfrentamento de situações novas e desconhecidas que exijam algum conhecimento matemático.

Entendemos que o aprofundamento das investigações e atividades embasadas em sala de sala de aula com Modelagem Matemática a consolidará como uma metodologia, que auxilia professores e alunos no processo de ensino e de aprendizagem. Assim, concordamos com Caldeira (2004) quando diz que a incorporação da Modelagem Matemática no âmbito das escolas depende da mudança de postura de professores e estudantes e não precisa esperar que a escola, enquanto sistema mude.

\section{Considerações finais}

A experiência adquirida com o desenvolvimento da Modelagem Matemática em duas turmas regulares do Ensino Médio Profissionalizante permite algumas considerações em relação à sua utilização. O Colégio Estadual Agrícola possui características diferenciadas da maioria das escolas, por desenvolver o ensino e atividades em tempo praticamente integral e possuir um corpo discente, constituído, na sua maioria, por filhos de agricultores.

A questão colocada para a investigação buscou conhecer as implicações da experiência com a Modelagem Matemática no contexto do Ensino Médio Profissionalizante para a prática escolar. A experiência possibilitou refletir sobre alguns aspectos considerados importantes nesta pesquisa para a prática escolar. A importância de desenvolver um trabalho contextualizado, a partir da escolha do tema pelos estudantes, que era parte das atividades atuais e de suas vidas profissionais futuras. A Modelagem ainda favoreceu em muitos momentos a construção, a compreensão e a resignificação dos conteúdos matemáticos estudados, além de mostrar a aplicabilidade desses conteúdos em situações mais específicas na área da agricultura.

Mesmo em momentos difíceis, como aqueles vividos durante a realização da experiência, em que o desejo de proporcionar um ensino com significado e compreensão se confrontava com a pressão dos estudantes para o cumprimento da programação definida para a série, o diálogo foi mantido permanentemente, pois ganhou força nas reflexões proporcionadas pela experiência. Assim, refletimos sobre a cultura da pressa e da simplificação e da quantidade, em detrimento da qualidade dos conteúdos trabalhados.

Os desafios para as inovações de práticas diferenciadas em sala de aula sempre existirão, principalmente enquanto persistir a tradição escolar que deixa a responsabilidade do processo de ensino e aprendizagem apenas para 
o professor e, ao aluno o papel de mero executor de atividades. Entretanto, esse desafio parece empolgar muitos educadores, trata-se de um processo educativo que envolve os atores principais da escola: alunos e professores.

A Modelagem Matemática, na forma concebida por Burak, pode trazer contribuições aos papéis atribuídos ao professor e estudantes, no processo de ensino e aprendizagem, que promova nos estudantes a criticidade e a autonomia e o desenvolvimento de competências complexas capazes de ajudá-los nas mais distintas situações de suas vidas. E, no caso relatado, para os estudantes do Ensino Médio Profissionalizante, conforme as discussões apresentadas neste capítulo.

\section{Referências}

ANDRÉ, M. E. D. A. Etnografia da prática escolar. Campinas: Papirus, 1995. (Série Prática Pedagógica).

BRASIL. Secretaria de Educação Média e Tecnológica. Parâmetros Curriculares Nacionais. Brasília: MEC, 1999.

BURAK, D. Modelagem matemática: uma metodologia alternativa para o ensino de matemática na $5^{\mathrm{a}}$ série. 185 f. Dissertação (Mestrado em Educação Matemática). Universidade Estadual Paulista Júlio Mesquita Filho, Rio Claro, 1987.

. Modelagem matemática: ações e interações no processo de ensinoaprendizagem. Tese (Doutorado em Educação) - Universidade Estadual de Campinas, Campinas, 1992.

. Formação dos pensamentos algébrico e geométrico: uma experiência com modelagem matemática. Pró-Mat. Paraná, Curitiba, v. 1,n. 1, p.32-41, 1998.

. A modelagem matemática e a sala de aula. In: Encontro Paranaense de Modelagem em Educação Matemática - I EPMEM, 1, 2004, Londrina. Anais... Londrina: UEL, 2004. p. 1-10.

CALDEIRA, A D. Modelagem matemática: possibilidades e perspectivas. In: Encontro Paranaense de Modelagem em Educação Matemática, 2004, Londrina: Anais... Londrina: UEL, 2004. 1 CD - ROM.

DANTE, L. R. Algumas reflexões sobre educação matemática. Temas e Debates, Rio Claro: ano IV, n 3, 1991. (Sociedade Brasileira de Educação Matemática). 
HOFF, M. S. A matemática na escola nos anos 80-90: críticas e tendências renovadoras. Cadernos de Pesquisa. São Paulo, n. 98, ago, 1996.

MACHADO, N. J. Matemática e realidade. 5. ed. São Paulo: Cortez, 2001.

SCHEFFER, N. F.; CAMPAGNOLLO, A. J. Modelagem matemática: uma alternativa para ensino-aprendizagem da matemática no meio rural. Zetetiké, Campinas: v. 6, n.10, jul./dez. 1998. 